(C) 2015 IEEE. Personal use of this material is permitted. Permission from IEEE must be obtained for all other uses, in any current or future media, including reprinting/republishing this material for advertising or promotional purposes, creating new collective works, for resale or redistribution to servers or lists, or reuse of any copyrighted component of this work in other works. 


\title{
Delta-connected Cascaded H-Bridge Multilevel Photovoltaic Converters
}

\author{
Yifan Yu, Georgios Konstantinou, Christopher D. Townsend, \\ Ricardo P. Aguilera, Branislav Hredzak and Vassilios G. Agelidis \\ Australian Energy Research Institute and School of Electrical Engineering and Telecommunications, \\ University of New South Wales (UNSW Australia), Sydney, 2052, NSW, Australia. \\ yifan.yu@student.unsw.edu.au, g.konstantinou@unsw.edu.au, c.townsend@unsw.edu.au, \\ ricardo.aguilera@unsw.edu.au,b.hredzak@unsw.edu.au, vassilios.agelidis@unsw.edu.au
}

\begin{abstract}
Multilevel cascaded H-bridge converters are becoming popular for next generation large-scale photovoltaic power converters. However, the power generation levels in the three phases can be significantly unequal, especially in a large plant, owing to the non-uniform irradiance levels and/or ambient temperatures. This paper proposes the delta-connected cascaded H-bridge converter for large-scale photovoltaic farms. Compared to the existing star connection, the delta connection reduces the converter overrating required. Experimental results obtained from a $430 \mathrm{~V}, 10 \mathrm{~kW}$, three-phase, seven-level, delta connected cascaded H-bridge converter prototype are provided to demonstrate the superiority of the delta connection.
\end{abstract}

Keywords-ac-dc power converters, cascaded H-bridge converter, multilevel converter, photovoltaics.

\section{INTRODUCTION}

The Cascaded H-Bridge (CHB) multilevel converter is considered as one of the most promising configurations for next-generation large-scale photovoltaic (PV) power plants [1]-[14]. With multilevel waveform synthesis, the switching frequency of semiconductor devices can be reduced greatly without affecting the harmonic performance [15]. Also the redundancy of multilevel converters improves the system availability [16]. The PV power generation levels in each bridge are unlikely to be equal, owing to the non-uniform solar irradiance, unequal ambient temperatures, partial shading and/or inconsistent module degradation.

The most common configuration presented in the literature is the star connection [17]-[22]. A Fundamental Frequency Zero-Sequence Injection (FFZSI) method presented in [18] is able to generate three-phase balanced grid currents under the inter-phase power imbalance. Advanced methods to achieve the inter-phase power balance were derived in [17], [19]-[22] to minimize the required converter output voltages, and thus enabling the converter to operate under more severe inter-phase power imbalance cases. However, extremely severe power imbalance scenarios still cannot be dealt with, even when the converter is considerably overrated by increasing the number of series connected bridges compared to that required in normal balanced operation.

The objective of this paper is to propose the deltaconnected $\mathrm{CHB}$ converter, which has been not explored in the literature of large-scale PV applications. Subsequent analysis demonstrates that the delta connection, compared to its star- connected counterpart, offers superior power balance capability dealing with inter-phase power imbalance.

The rest of the paper is organized as follows. Section II presents the delta connected CHB converter for large-scale PV plants. Simulation results based on Matlab/PLECS are presented in Section III. Experimental waveforms based on a $430 \mathrm{~V}, 10 \mathrm{~kW}$, three-phase, seven-level, delta connected CHB converter prototype are provided in Section IV.

\section{Delta-CONNECTED CHB CONVERTER}

Fig. 1 illustrates the layout of the three-phase, seven-level CHB converter for large-scale PV plants in both star and delta connections. Each phase leg consists of $N$ bridges, and the converter output voltages feature $(2 N+1)$-level waveforms. Each H-bridge could be fed by multiple PV strings via independent dc-dc converters. Galvanic isolation can be provided in the dc-dc conversion stage (high-frequency transformers typically preferred) to isolate the PV modules from the grid, because most commercial PV modules are designed to withstand less than $1000 \mathrm{~V}$ between the active part and the grounded frame [23]. Compared to the star connection investigated in the literature [17]-[22], the delta connection in Fig. 1 requires a bridge number of $\sqrt{3}$ times larger, since one phase leg must synthesize the line-to-line voltage.

When the power generation levels in the three phases become unequal, three-phase line currents can become unbalanced. Nevertheless, balanced line currents are usually required by grid codes. As a result, a zero-sequence current needs to be injected to the converter currents to provide three-phase balanced line currents. It is similar to the injection of zerosequence voltage in the star connection.

Fig. 2 demonstrates the phasor diagram of the deltaconnected $\mathrm{CHB}$ converter under unbalanced power generation. In this case, more power is generated in phase $a b$ than the other two phases. The injected zero-sequence current vector $\mathbf{I}^{\mathbf{0}}$ contributes to the power transfer among the three phases. For the case illustrated in Fig. 2, $\mathbf{I}^{\mathbf{0}}$ helps transfer the excessive power in phase $a b$ to phases $b c$ and $c a$. Since the zero-sequence current only flows within the delta loop, the three-phase line currents are hence unaffected. Therefore, viewed from the grid side, the converter produces three-phase balanced grid currents as required, just like the balanced operation. The converter output voltage vectors $\mathbf{V}_{\mathbf{a b}}, \mathbf{V}_{\mathbf{b c}}, \mathbf{V}_{\mathbf{c a}}$ are not drawn in Fig. 2, 

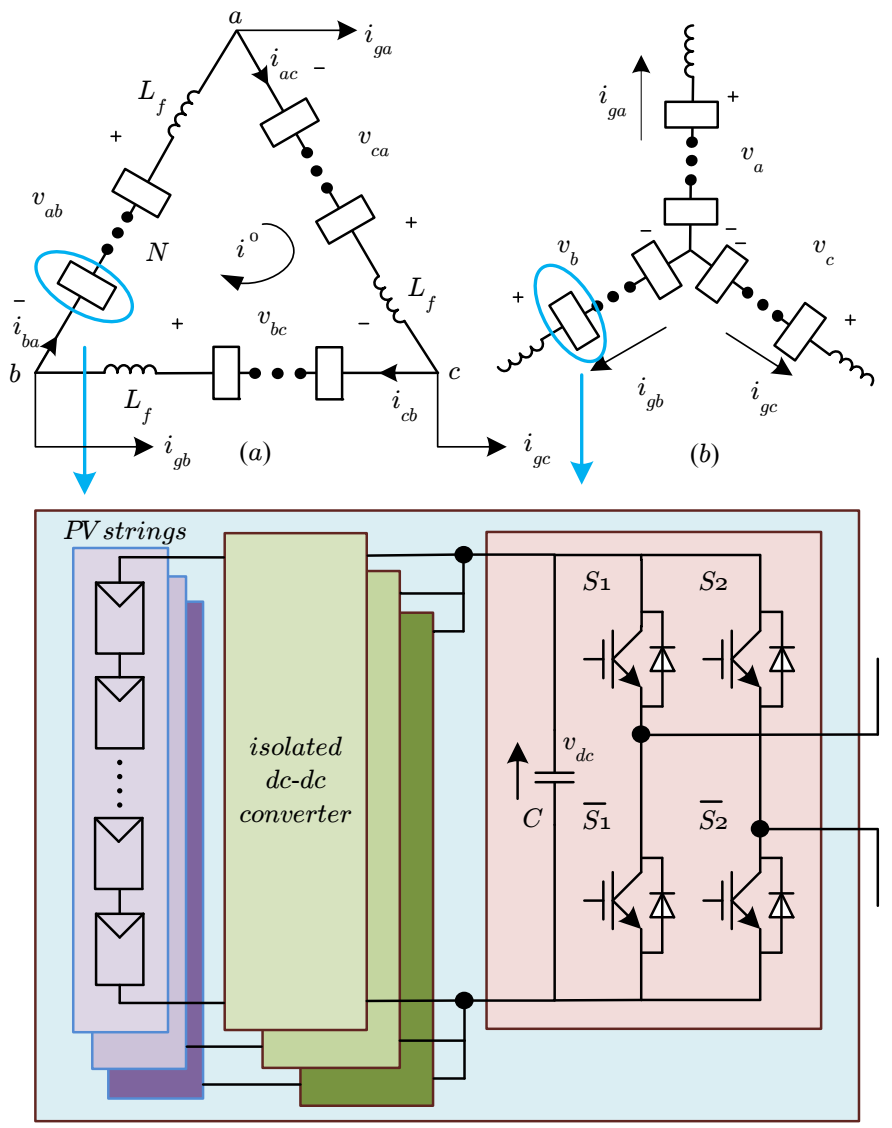

(c)

Fig. 1. Three-phase, $(2 N+1)$-level cascaded H-bridge converter: (a) delta connection, (b) star connection, (c) H-bridge.

as they change corresponding to the converter current vectors $\left(\mathbf{I}_{\mathbf{a b}}, \mathbf{I}_{\mathbf{b c}}, \mathbf{I}_{\mathbf{c a}}\right)$.

The power generation ratios $\left(\lambda_{a b}, \lambda_{b c}, \lambda_{c a}\right)$ are defined to reflect the actual power generation levels in the three phase legs [17]:

$$
\lambda_{i}=\frac{p_{i}}{P_{n o m} / 3}, \quad i \in\{a b, b c, c a\}
$$

where $P_{n o m}$ denotes the three-phase nominal power, and $p_{a b}$, $p_{b c}, p_{c a}$ denote the actual power generation in each phase. The average power generation ratio $\vec{\lambda}$ can be calculated as:

$$
\bar{\lambda}=\frac{\lambda_{a b}+\lambda_{b c}+\lambda_{c a}}{3} .
$$

The active power generated by each phase should be equal to the generated $\mathrm{PV}$ power:

$$
\begin{aligned}
& V_{g} I_{g} / \sqrt{3}+V_{g} I^{0} \cos (\pi / 6-\theta)=\lambda_{a b} P_{n o m} / 3 \\
& V_{g} I_{g} / \sqrt{3}+V_{g} I^{0} \cos (3 \pi / 2-\theta)=\lambda_{b c} P_{n o m} / 3 \\
& V_{g} I_{g} / \sqrt{3}+V_{g} I^{0} \cos (5 \pi / 6-\theta)=\lambda_{c a} P_{n o m} / 3
\end{aligned}
$$

The amplitude and phase angle of the required zerosequence current to balance the phase leg power levels can

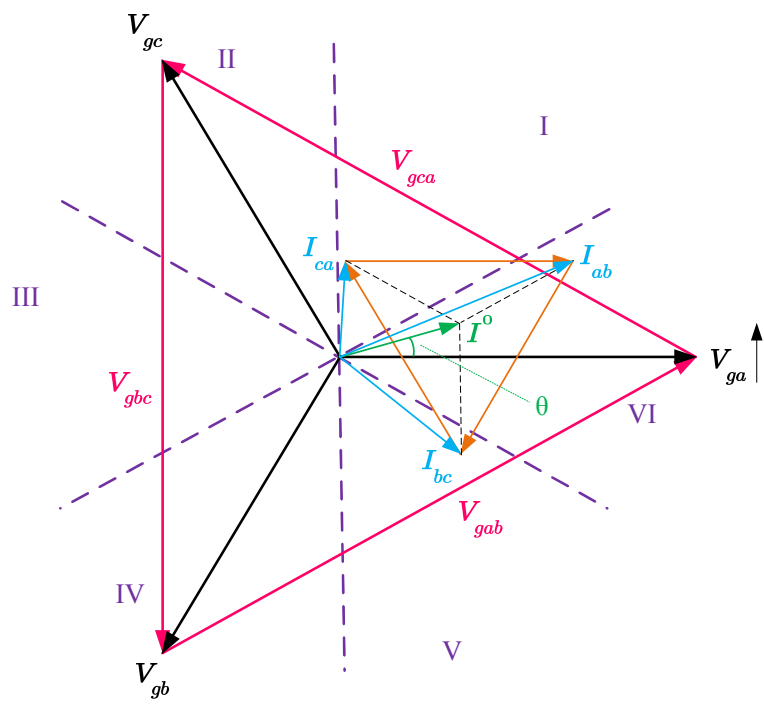

Fig. 2. The phasor diagram of the delta-connected CHB converter under the unbalanced operation.

TABLE I.

Zero-Sequence Current Vector Sector

\begin{tabular}{c|c} 
Power Generation Ratios & Sector \\
\hline$\lambda_{b c}<\lambda_{c a}<\lambda_{a b}$ & (I) \\
\hline$\lambda_{b c}<\lambda_{a b}<\lambda_{c a}$ & (II) \\
\hline$\lambda_{a b}<\lambda_{b c}<\lambda_{c a}$ & (III) \\
\hline$\lambda_{a b}<\lambda_{c a}<\lambda_{b c}$ & (IV) \\
\hline$\lambda_{c a}<\lambda_{a b}<\lambda_{b c}$ & (V) \\
\hline$\lambda_{c a}<\lambda_{b c}<\lambda_{a b}$ & (VI) \\
\hline
\end{tabular}

be calculated as:

$$
\begin{aligned}
& I^{0}=\frac{\sqrt{2} \Gamma_{\Delta} P_{n o m}}{9 V_{g}}, \\
& \theta= \begin{cases}\pi / 6+\sin ^{-1}\left(\frac{\sqrt{6}\left(\lambda_{c a}-\lambda_{b c}\right)}{2 \Gamma_{\Delta}}\right) & \text { Sectors (I), (VI) } \\
5 \pi / 6+\sin ^{-1}\left(\frac{\sqrt{6}\left(\lambda_{b c}-\lambda_{a b}\right)}{2 \Gamma_{\Delta}}\right) & \text { Sectors (II), (III) , } \\
3 \pi / 2+\sin ^{-1}\left(\frac{\sqrt{6}\left(\lambda_{a b}-\lambda_{c a}\right)}{2 \Gamma_{\Delta}}\right) & \text { Sectors (IV), (V) }\end{cases}
\end{aligned}
$$

where $\Gamma_{\Delta}$ is defined as:

$$
\Gamma_{\Delta}=\sqrt{\left(\lambda_{a b}-\lambda_{b c}\right)^{2}+\left(\lambda_{b c}-\lambda_{c a}\right)^{2}+\left(\lambda_{a b}-\lambda_{c a}\right)^{2}},
$$

and the sector can be determined via Table I by three-phase power generation ratios $\lambda_{a b}, \lambda_{b c}, \lambda_{c a}$.

In the star connection, the injection of the zero-sequence voltage increases the required converter output voltages, whereas the dc-side capacitor voltage is usually designed to be constant. Therefore, when the inter-phase power imbalance becomes severe and a larger zero-sequence voltage is needed, the converter reaches saturation easily. However, the scenario in the delta connection presented in this paper is different. When the inter-phase power imbalance occurs, the symmetrical component of the converter currents and the line currents decrease from the nominal value, owing to the drop of the 


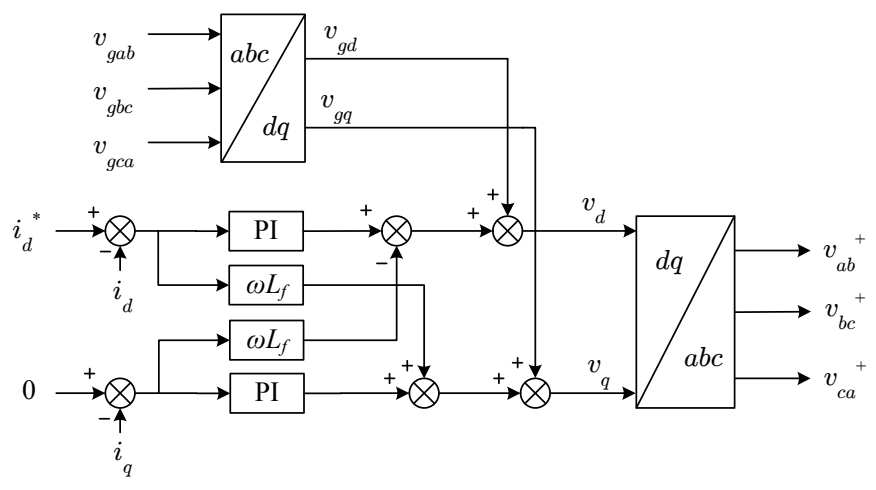

Fig. 3. The overall power balance loop.

overall power. Hence, the increase of the converter currents caused by the zero-sequence current can be alleviated, and the required converter overrating is reduced.

The required current rating during the nominal operation can be written as:

$$
I_{n o m}=\frac{\sqrt{2} P_{n o m}}{3 V_{g}} .
$$

The maximum required current rating occurs when two phase generate full power and the other phase stands idle, i.e. $\left(\lambda_{a b}, \lambda_{b c}, \lambda_{c a}\right)=(1,1,0),(1,0,1)$ and $(0,1,1)$ :

$$
\frac{I_{\max }}{I_{\text {nom }}}=\frac{2 \sqrt{3}}{3} \approx 1.155 \text {. }
$$

The result shows that a delta-connected CHB converter with the current overrating of $15.5 \%$ can theoretically tolerate all possible power imbalance cases. However, in the star connection [17], much higher voltage redundancy has to be left to tolerate the same imbalance cases.

The overall balance loop, based on the conventional decoupled $d q$ control, regulates the positive sequence component of the converter currents (Fig. 3), as if an equal amount of power were generated by the three phases. The active power reference of each bridge is calculated by comparing the measured dcside capacitor voltage $v_{d c(i j)}(i=a b, b c, c a ; j=1,2,3)$ to its command $v_{d c}^{*}$. The phase power reference can then be obtained by adding the three bridge power references in the phase leg, and the overall power by adding the three phase power references. The zero-sequence current, calculated in (5), is added after this stage.

\section{Simulation Results}

A $3.9 \mathrm{kV}, 3.2 \mathrm{MW}$, three-phase, seven-level, deltaconnected CHB converter is simulated in Matlab/PLECS to validate the feasibility of the presented configuration. The converter parameters used in the simulation are listed in Table II. The conventional Phase Shift Pulse Width Modulation (PSPWM) is implemented with a carrier frequency of $600 \mathrm{~Hz}$ [17]. Please note that CHB converters can be extended to more levels; therefore, the higher voltage/power can be reached in real applications. The seven-level CHB converter is simulated here as an example only. The carrier frequency can also be
TABle II. Delta-connected Converter Parameters (SIMUlation)

\begin{tabular}{c|c} 
Parameters & Values \\
\hline Grid Voltage, $V_{g}$ & $3.9 \mathrm{kV}$ \\
\hline Nominal Power, $P_{n o m}$ & $3.2 \mathrm{MW}$ \\
\hline dc-side Capacitor Voltage, $v_{d c}$ & $2200 \mathrm{~V}$ \\
\hline Filtering Inductance (per phase), $L_{f}$ & $5 \mathrm{mH}$ \\
\hline Carrier Frequency, $f_{s}$ & $600 \mathrm{~Hz}$
\end{tabular}

TABLE III. CURRENT TOTAL HARMONIC Distortion

\begin{tabular}{c|c|c|c|c|c|c}
\multirow{2}{*}{ Operation } & \multicolumn{3}{|c|}{ Converter Currents } & \multicolumn{3}{c}{ Line Currents } \\
\cline { 2 - 7 } & $i_{a b}$ & $i_{b c}$ & $i_{c a}$ & $i_{g a}$ & $i_{g b}$ & $i_{g c}$ \\
\hline Balanced & $2.64 \%$ & $2.63 \%$ & $2.65 \%$ & $2.19 \%$ & $2.16 \%$ & $2.17 \%$ \\
\hline Unbalanced & $6.45 \%$ & $2.82 \%$ & $2.74 \%$ & $2.71 \%$ & $2.56 \%$ & $2.63 \%$ \\
\hline
\end{tabular}

TABLE IV. EXPERIMENTAL PROTOTYPE PARAMETERS

\begin{tabular}{c|c} 
Parameters & Values \\
\hline Grid Voltage, $V_{g}$ & $430 \mathrm{~V}$ \\
\hline Three-phase Nominal Power, $P_{n o m}$ & $10 \mathrm{~kW}$ \\
\hline Filtering Inductance per phase, $L_{f}$ & $10 \mathrm{mH}(0.06$ p.u. $)$ \\
\hline MPP of PV Array & $239.4 \mathrm{~V}, 4.645 \mathrm{~A}$ \\
\hline dc-side Capacitor Voltage, $v_{d c}$ & $239.4 \mathrm{~V}$ \\
\hline Carrier Frequency, $f_{s}$ & $1500 \mathrm{~Hz}$ \\
\hline
\end{tabular}

further reduced to be near the fundamental frequency, as the number of levels increases.

Fig. 4 shows the balanced operation with three phases generating equal amount of power. Both the converter currents (Fig. 4(b)) and the line-currents (Fig. 4(c)) are symmetrical. The seven-level voltage waveforms generate currents with low harmonic distortion, as shown in Table III. Since the power generation levels in the three phases are equal, no zerosequence current is injected (Fig. 4(c)).

The unbalanced operation, when the power generated in phase $a b$ reduces to $50 \%$ of its nominal value with no change in the other two phases, is shown in Fig. 5. It corresponds to $\lambda_{a b}=0.5, \lambda_{b c}=\lambda_{c a}=1$. Owing to the injection of the zero-sequence current to deal with the unequal power generation levels, the converter currents (Fig. 5(b)) are no longer symmetrical. However, the line currents (Fig. 5(c)) are still symmetrical as required by grid codes, as the zero-sequence current cancels. This confirms the feasibility of the presented delta-connected CHB converter.

\section{EXPERIMENTAL RESULTS}

Experimental results obtained from a $430 \mathrm{~V} 10 \mathrm{~kW}$ laboratory prototype are also provided to show the improved power balance capability of the delta connection. The converter parameters are summarized in Table IV. Each H-bridge is fed by a TerraSAS programmable PV simulator $(600 \mathrm{~V} 8.3 \mathrm{~A})$. The Maximum Power Point (MPP) of each simulation is programmed at $239.4 \mathrm{~V} 4.645 \mathrm{~A}$ under the nominal condition $\left(1000 \mathrm{~W} / \mathrm{m}^{2}\right.$ and $\left.25^{\circ} \mathrm{C}\right)$. PS-PWM is used in the experiment with a carrier frequency of $1500 \mathrm{~Hz}$. With three bridges in the phase leg, the converter output voltages feature seven-level waveforms with an equivalent switching frequency of $9 \mathrm{kHz}$. The experimental setup is shown in Fig. 6.

The solar irradiance of the three PV simulators in phase $a b$ is decreased from $1000 \mathrm{~W} / \mathrm{m}^{2}$ to $500 \mathrm{~W} / \mathrm{m}^{2}$ to emulate the 


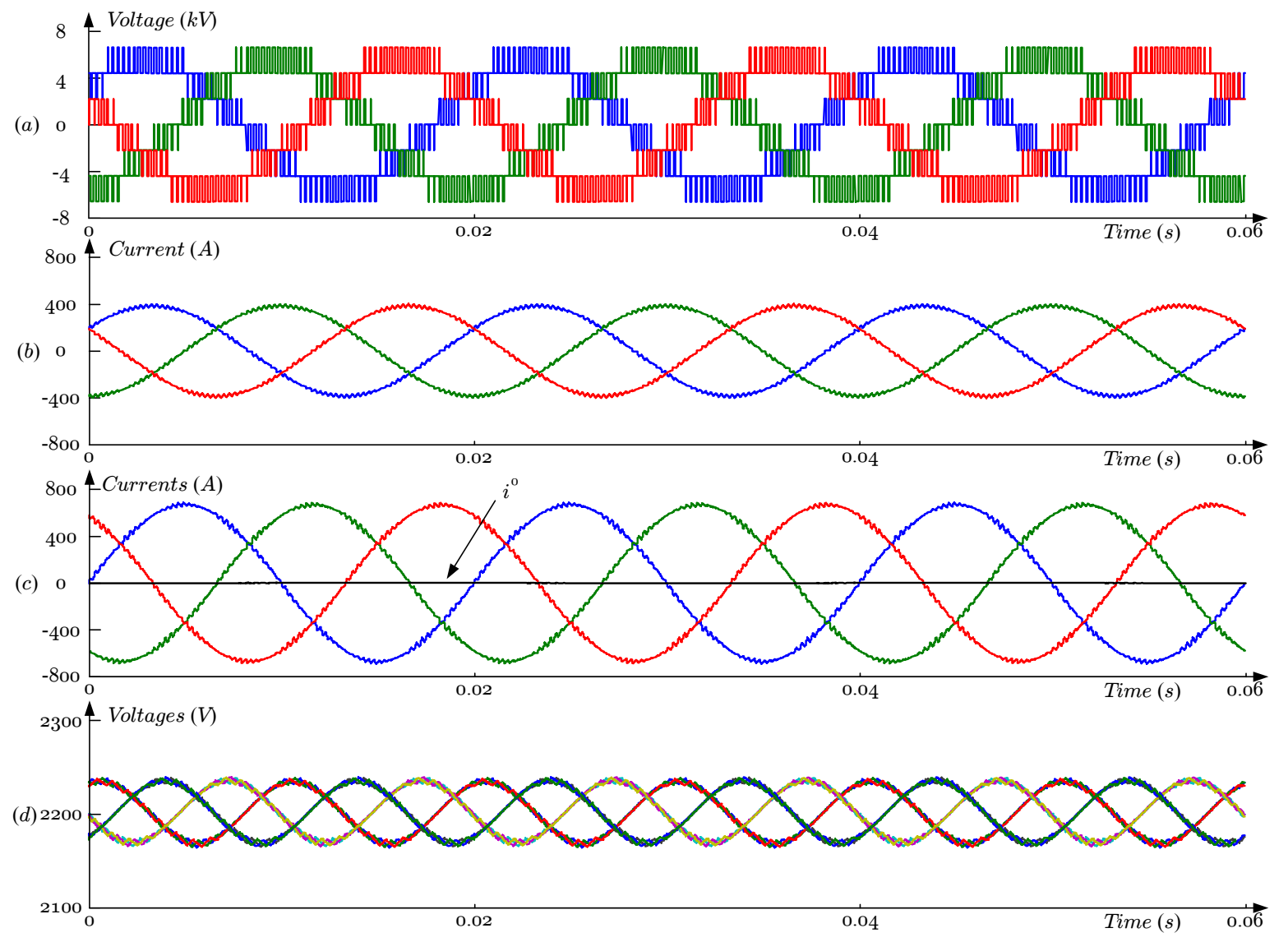

Fig. 4. Balanced operation ( $\lambda_{a b}=\lambda_{b c}=\lambda_{c a}=1$ ): (a) converter output voltages, (b) converter currents, (c) line currents and zero-sequence current, (d) dc-side capacitor voltages.

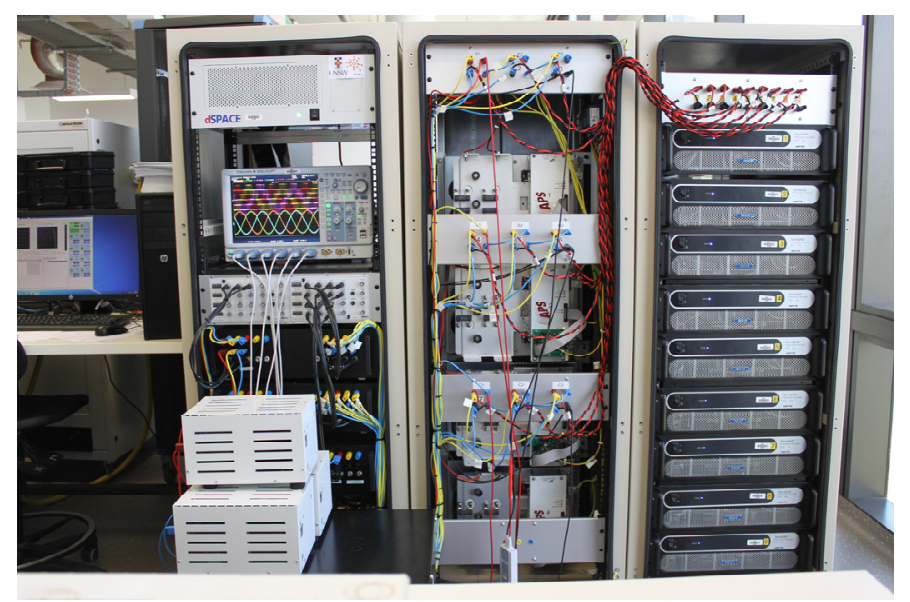

Fig. 6. Delta-connected, three-phase, seven-level CHB converter prototype.

unbalanced power generation. Due to the lack of dc-dc conversion stages, the actual power generation level is approximately $50 \%$ of its nominal value. Fig. 7(a) shows the three-phase converter output voltages and converter currents under inter-phase power imbalance $\left(\lambda_{a b}=1, \lambda_{b c}=0.5, \lambda_{c a}=1\right)$. The converter currents are no longer symmetrical, since phase $a b$ generates less power than the other two phases. However, the three-phase line currents (Fig. 7(b)) still feature symmetrical sinusoidal waveforms with an average rms value of $10.3 \mathrm{~A}$. The zerosequence current, which only flows within the delta loop, deals with the unequal power generation levels. Since the imbalance case cannot be dealt with by the star connection [22], the superiority of the presented delta connection in terms of the power balance capability is thus confirmed.

\section{CONCLUSion}

This paper proposes the delta-connected cascaded H-bridge converters for large-scale photovoltaic power plants. Compared to star-connected converters presented in the literature, the presented delta connection significantly reduces the converter overrating, required to deal with the inter-phase power imbalance presented in PV applications. Both the simulation results and experimental waveforms based a $430 \mathrm{~V}, 10 \mathrm{~kW}$, three-phase, seven-level, delta-connected cascaded H-bridge converter prototype confirms the superiority of delta-connected converters in terms of the inter-phase power balance capability.

\section{REFERENCES}

[1] S. Kouro, J. I. Leon, D. Vinnikov, L. G. Franquelo, "Grid-connected photovoltaic systems: an overview of recent research and emerging PV converter technology," IEEE Ind. Electron. Mag., vol. 9, no. 1, pp. 47-61, Mar. 2015.

[2] E. Villanueva, P. Correa, J. Rodriguez, and M. Pacas, "Control of a single-phase cascaded H-bridge multilevel converter for grid-connected photovoltaic systems," IEEE Trans. Ind. Electron., vol. 56, no. 11, pp. 4399-4406, Nov. 2009. 


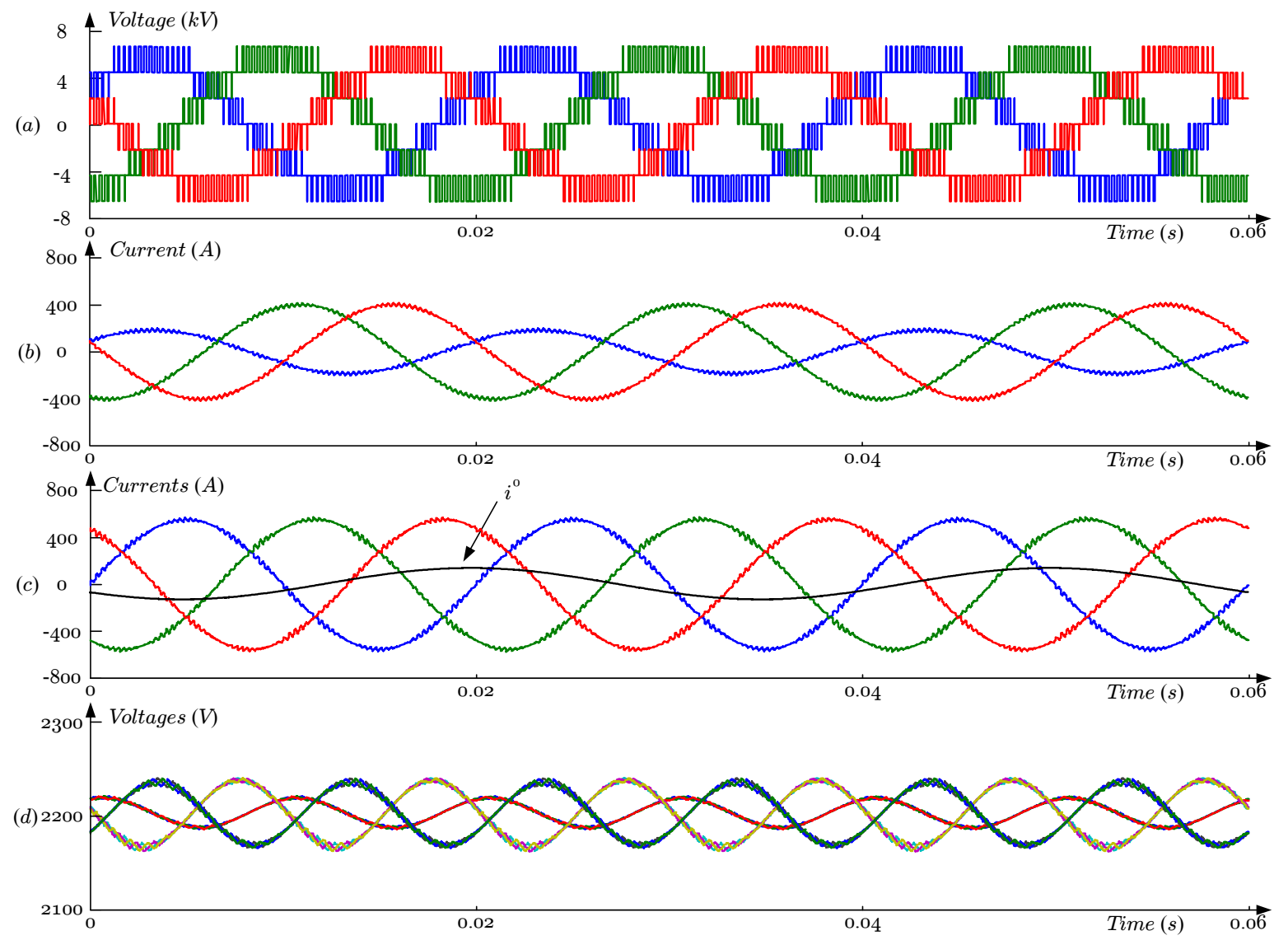

Fig. 5. Balanced operation $\left(\lambda_{a b}=0.5, \lambda_{b c}=\lambda_{c a}=1\right.$ ): (a) converter output voltages, (b) converter currents, (c) line currents and zero-sequence current, (d) dc-side capacitor voltages.

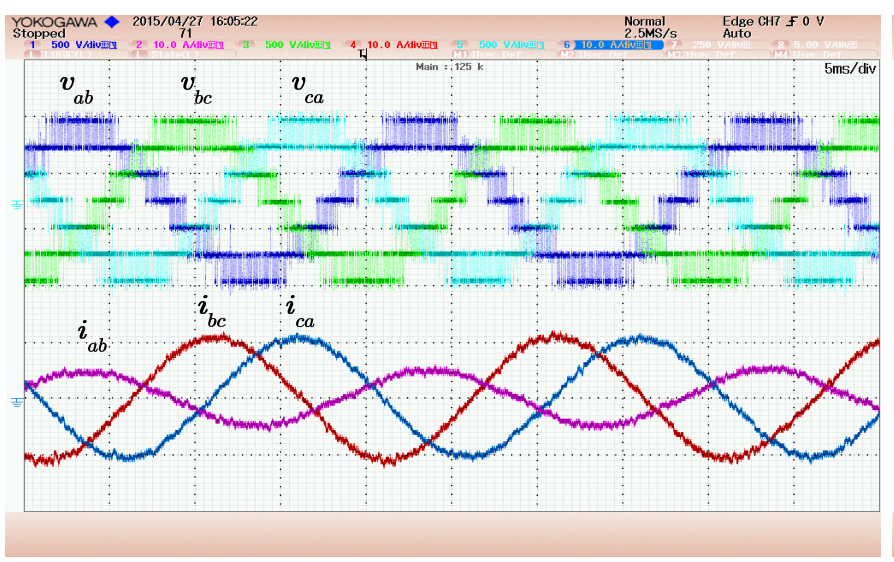

(a)

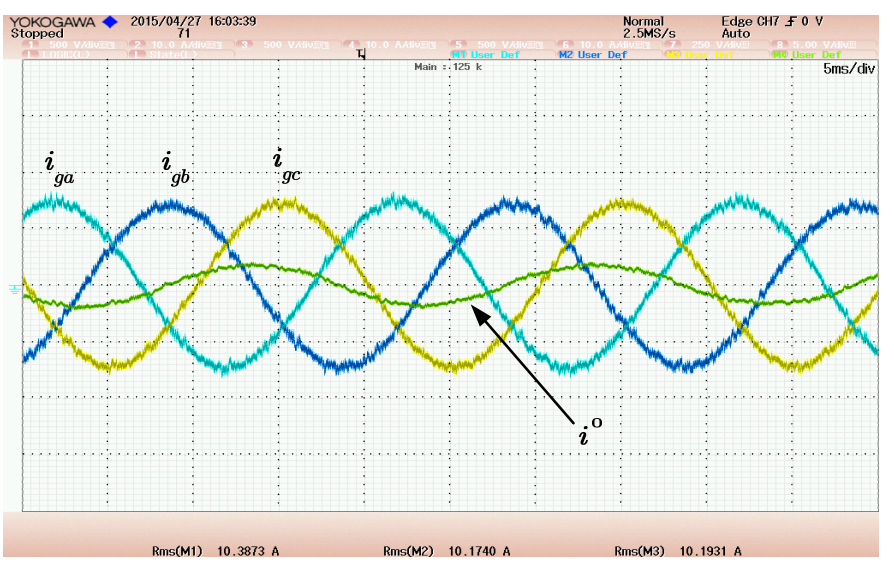

(b)

Fig. 7. Unbalanced operation: (a) three-phase converter output voltages and converter currents; (b) line currents and zero-sequence current. (a) CH1: converter output voltage of phase $a b v_{a b}, \mathrm{CH} 2$ : converter current of phase $a b i_{a b}, \mathrm{CH} 3$ : converter output voltage of phase $b c v_{b c}$, $\mathrm{CH} 4$ : converter current of phase $b c$ $i_{b c}$, CH5: converter output voltage of phase $c a v_{c a}$, CH6: converter current of phase $c a i_{c a}$. CH1, CH3, CH5: 500 V/div; CH2, CH4, CH6: 10 A/div. (b) M1: line current of phase $a i_{g a}$, M2: line current of phase $b i_{g b}$, M3: line current of phase $c i_{g c}$, M4: zero-sequence current $i^{0}$. M1, M2, M3, M4: 10 A/div.

[3] J. Chavarria, D. Biel, F. Guinjoan, C. Meza, and J. Negroni, "Energybalance control of PV cascaded multilevel grid-connected converters under level-shifted and phase-shifted PWMs," IEEE Trans. Ind. Electron., vol. 60, no. 1, pp. 98-111, Jan. 2013.

[4] J. Sastry, P. Bakas, H. Kim, L. Wang, and A. Marinopoulos, "Evaluation of cascaded H-bridge inverter for utility-scale photovoltaic systems," Renewable Energy, vol. 69, pp. 208-218, Sep. 2014.
[5] L. Liu, H. Li, Y. Xue, and W. Liu, "Decoupled active and reactive power control for large-scale grid-connected photovoltaic systems using cascaded modular multilevel converters," IEEE Trans. Power Electron., vol. 30, no. 1, pp. 176-187, Jan. 2015.

[6] L. Liu, H. Li, Y. Xue, and W. Liu, "Reactive power compensation and optimization strategy for grid-interactive cascaded photovoltaic systems," IEEE Trans. Power Electron., vol. 30, no. 1, pp. 188-202, Jan. 2015. 
[7] S. Essakiappan, H. S. Krishnamoorthy, P. Enjeti, R. S. Balog, and S. Ahmed, "Multilevel medium-frequency link inverter for utility scale photovoltaic integration," IEEE Trans. Power Electron., vol. 30, no. 7, pp. 3674-3684, Jul. 2015.

[8] M. R. Islam, Y. Guo, and J. Zhu, "A high-frequency link multilevel cascaded medium-voltage converter for direct grid integration of renewable energy systems," IEEE Trans. Power Electron., vol. 29, no. 8, pp. 41674182, Aug. 2014.

[9] W. Zhao, H. Choi, G. Konstantinou, M. Ciobotaru, and V. G. Agelidis, "Cascaded H-bridge multilevel converter for large-scale PV gridintegration with isolated DC-DC stage," in Proc. IEEE PEDG 2012, pp. 849-856.

[10] M. Coppola, F. D. Napoli, P. Guerriero, D. Iannuzzi, D. Daliento, A. D. Pizzo, "An FPGA-based advanced control strategy of a grid-tied PV CHB inverter," IEEE Trans. Power Electron. (early access) (DOI: 10.1109/TPEL.2015.2405416)

[11] Y. Shi, R. Li, H. Li, and Y. Xue, "High-frequency-link based grid-tied PV system with small dc-link capacitor and low-frequency ripple-free maximum power point tracking," IEEE Trans. Power Electron. (early access) (DOI: 10.1109/TPEL.2015.2411858)

[12] Y. Zhou, and H. Li, "Analysis and suppression of leakage current in cascaded-multilevel-inverter-based PV systems," IEEE Trans. Power Electron., vol. 29, no. 10, pp. 5265-5277, Oct. 2014.

[13] D. Sun, B. Ge, W. Liang, H. Abu-Rub, and F. Peng, "An energy stored quasi-Z-source cascade multilevel inverter based photovoltaic power generation system," IEEE Trans. Ind. Electron. (early access) (DOI: 10.1109/TIE.2015.2407853)

[14] P. Sochor, and H. Akagi, "Theoretical comparison in energy-balancing capability between star- and delta-configured modular multilevel cascade inverters for utility-scale photovoltaic systems," IEEE Trans. Power Electron. (early access) (DOI: 10.1109/TPEL.2015.2442261)
[15] J. S. Lai, and F. Z. Peng, "Multilevel converters - a new breed of power converters, IEEE Tran. Ind. Appl., vol. 32, no. 3, pp. 509-517, May/Jun. 1996.

[16] Y. Yu, G. Konstantinou, B. Hredzak, and V. .G. Agelidis, ”Operation of cascaded H-bridge multilevel converters for large-scale photovoltaic power plants under bridge failures," IEEE Trans. Ind. Electron. (early access) (DOI: 10.1109/TIE.2015.2434995)

[17] Y. Yu, G. Konstantinou, B. Hredzak, and V. G. Agelidis, "Power balance of cascaded H-bridge multilevel converters for large-scale photovoltaic grid integration," IEEE Trans. Power Electron. (early access) (DOI: 10.1109/TPEL.2015.2406315)

[18] C. D. Townsend, T. Summers, and R. Betz, "Control and modulation scheme for a cascaded H-bridge multi-level converter in large scale photovoltaic systems," in Proc. IEEE ECCE 2012, pp. 3707-3714.

[19] S. Rivera, B. Wu, S. Kouro, and D. Zhang, "Cascaded H-bridge multilevel converter topology and three-phase balance control for large scale photovoltaic systems," in Proc. IEEE PEDG 2012, pp. 690-697.

[20] B. Xiao, L. Hang, J. Mei, C. Riley, L. Tolbert, and B. Ozpineci, "Modular cascaded H-bridge multilevel PV inverter with distributed MPPT for grid-connected applications," IEEE Trans. Ind. Appl., vol. 51, no. 2, pp. 1722-1731, Mar--Apr. 2015.

[21] S. Rivera, B. Wu, S. Kouro, and D. Zhang, "Cascaded H-bridge multilevel converter topology and three-phase balance control for large scale photovoltaic systems," in Proc. IEEE PEDG 2012, pp. 690-697.

[22] Y. Yu, G. Konstantinou, B. Hredzak, and V. G. Agelidis, "Power balance optimization of cascaded H-bridge multilevel converters for large-scale photovoltaic grid integration," IEEE Trans. Power Electron. (early access) (DOI: 10.1109/TPEL.2015.2407884)

[23] Thin-film Terrestrial Photovoltaic (PV) Modules - Design Qualification and Type Approval, IEC 61646, 2008. 